\title{
The Study of the Composite Material Go/CF/PTFE Tribological Property
}

\author{
Li-hu Wang ${ }^{1}$, Shou-ren Wang ${ }^{1, a}$,Dao-sheng Wen ${ }^{1}$,Gao-qi Wang ${ }^{1}$ and Li-ying Yang ${ }^{1}$ \\ ${ }^{1}$ School of Mechanical Engineering, Jinan University, Jinan 250022, China
}

\begin{abstract}
In this paper, the composite material Go/CF/PTFE tribological property was studied. The test of its mechanical property, and the fabrication of the filled PTEE composite material sample which is based on the technology of cold press molding and sinter molding proved that adding Go and CF moderately to the composite material was an efficient way to improve its mechanical property. Meanwhile the process of friction and wear trial and SEM analysis results of the micro-structure of wear pattern proved that the addition of the Go and CF tremendously improved the anti-wear property and that after the addition the plowing effect which took place on the material surface would turn into a kind of mixed wear effect that includes plowing effect and fatigue wear. Working as pinning and bridging, the Go which distributing uniformly in the matrix was able to improve the resistance and substantially resisted the crack propagation, therefore to a certain degree enhanced the intensity of composite material and prolong its lifespan.
\end{abstract}

\section{Introduction}

The PTFE is a kind of polymer with the great comprehensive property, such as the high tensile strength(range from $10 \mathrm{MPa}$ to $35 \mathrm{MPa}$ ), bending strength(range from $18 \mathrm{MPa}$ to $20 \mathrm{MPa}$ ), compressive strength(range from $18 \mathrm{MPa}$ to $27 \mathrm{MPa}$ ), impact strength(range from $24 \mathrm{MPa}$ to $31 \mathrm{MPa}$ ) and low friction coefficient (range from 0.13 to 0.16 ), which are attributed to its special supramolecular helical structure. But the insufficient property of wear resistance limited the its application of production, especially in the high speed and heavy load conditions which demanded the great property of wear resistance ${ }^{[1]}$. Recently, although many researchers have improved the property of wear resistance of PTFE by adding the compounds such as fiberglass, $\mathrm{SiO}_{2}$, tin bronze, $\mathrm{CF}$ and Go etc. to PTFE, few researchers have studied the mechanical property and wear resistance property which were affected by Go and CF at the same time. This paper includes the study where we added the some kinds of padding to PTFE to change the property, then investigated the affect of content of GO and CF on the mechanical property by several trials. We also have tested the friction coefficient by MMG-10 friction wear testing machine, then in order to analyze the wear mechanism we analyzed the Micro-structure of crack and fracture area deeply.

\section{The material of experiment and method}

\subsection{The manufacturing of composite material sample}

The manufactured composite material is consisted of PTFE used as matrix and Go and CF used as reinforcement. According to the different quantity of addition, the sample was divided into 10 groups which were distinguished by the mass fraction: Go( $1 \%, 2 \%, 3 \%)$, $\mathrm{CF}(1 \%, 2 \%, 3 \%)$. The specific quantity of adding units arrange is shown in Table 1. The original material specification and the manufacture factory are shown in Table 2. Before the trial, the Go and CF must be disposed by KH-550 silane coupling agent, and the procedure was that the solution with $8 \%$ water $+70 \%$ alcohol $+22 \%$ silane coupling agentwas prepared, then Go and CF were added to the solution according to Table 1 . When they were dissolved completely,the new solution should be placed into the ultrasonic oscillator for 2 minutes, then it was dried by the air-dry oven. Finally, the material was collected whose size is smaller than 300 microns by standard $\operatorname{sieve}^{[2]}$. The manufacturing procedure of composite material is shown as follows. First of all, the material which was weighed and took in a certain amount with the calculated mass fraction should be placed into mill pot in order to mix them and then corundum balls should be added to the sample with the proportion $7: 1$ (sample: balls) and sealed it. Secondly, the mill pot need to be evacuated to vacuum and filled it with argon gas whose concentration is $0.075 \mathrm{MPa}$ to mill the sample with $180 \mathrm{r} / \mathrm{min}$ revolving speed for 5 hours. Subsequently, finished sample was placed into the self-made mold (figure 1)for cold compression with $10 \mathrm{MPa} / \mathrm{min}$ compression rate. When the stress arrived $130 \mathrm{MPa}$, it

Corresponding author: sherman0158@163.com 
should be kept for 2 minutes. Then the sample was placed into electric furnace for sintering with the $60^{\circ} \mathrm{C} / \mathrm{h}$ heating rate. When the temperature rose to $327^{\circ} \mathrm{C}$, it should be kept for 0.5 hours, then the temperature rose to $375^{\circ} \mathrm{C}$ with the same rate and it was soaked for 2 hours. Finally, the sample was furnace cooled to room temperature. The technological parameters of sintering are shown in Figure 2. The sample after manufacturing should be individually ground coarsely, finely and accurately based on different test aims. .

Table 1. Preparation of GO / CF / PTFE composites sample

\begin{tabular}{lllllllllll}
\hline $\begin{array}{l}\text { Sample } \\
\text { number }\end{array}$ & $\mathbf{1}$ & $\mathbf{2}$ & $\mathbf{3}$ & $\mathbf{4}$ & $\mathbf{5}$ & $\mathbf{6}$ & $\mathbf{7}$ & $\mathbf{8}$ & $\mathbf{9}$ & $\mathbf{1 0}$ \\
\hline $\mathrm{PTFE} / \%$ & 100 & 89 & 79 & 69 & 88 & 78 & 68 & 87 & 77 & 67 \\
$\mathrm{CF} / \%$ & 0 & 10 & 20 & 30 & 10 & 20 & 30 & 10 & 20 & 30 \\
$\mathrm{Go} / \%$ & 0 & 1 & 1 & 1 & 2 & 2 & 2 & 3 & 3 & 3 \\
\hline
\end{tabular}

Table 2. Raw materials of Go/CF/PTFE composites

\begin{tabular}{ccc}
\hline Material Name & Specification & Manufacturer \\
\hline PTFE & Diameter of about $48 \mu \mathrm{m}$ & Dongguan prosperous plastic materials Co., \\
Ltd \\
CF & 7 layers & Global Technology \\
Silane coupler & Diameter of about $50 \mu \mathrm{m}$ & Zibo Kun Mao Da New Materials Co., Ltd \\
& KH-550 & Nanjing Creation Chemical Additives Co., \\
\end{tabular}

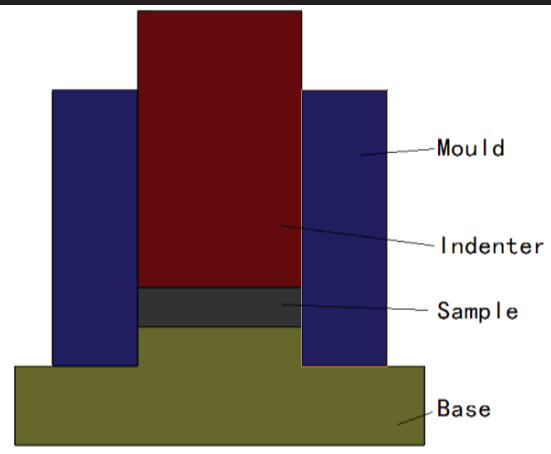

Figure 1. Schematic diagram of cold forming for sample in the mould

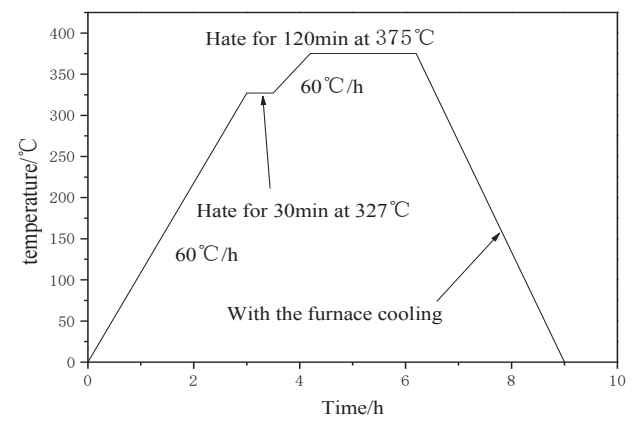

Figure 2. Sintering processes

\subsection{The mechanical property trial}

\subsubsection{The test of tensile property}

We tested the tensile strength of the sample we gained by electronic universal testing machine. Before the test, the sample should be molded into hexahedron structure with dimension of $40 \mathrm{~mm} \times 4 \mathrm{~mm} \times 4 \mathrm{~mm}$. Stretching rate was $2 \mathrm{~mm} / \mathrm{min}$, and the pre-streching rate was $1 \mathrm{~mm} / \mathrm{min}$. After the test of all 10 groups, the maximum and minimum results should be ignored, then calculated the average of the rest results.

\subsubsection{The test of bending property}

The bending strength of the samples in every group was tested by three point bending method. In this experiment, the span between two fulcrums on the clamp is $\mathrm{L}=30 \mathrm{~mm}$, and the load rate is $2 \mathrm{~mm} / \mathrm{min}$. There are 10 samples in each group to be tested then calculate the arithmetic average of the results.

\subsubsection{The test of compressive property}

We tested the compressive property by computer-controlled high-temperature universal testing machine. Before the test, the sample should be molded into hexahedron structure with dimension of $10 \mathrm{~mm} \times 4 \mathrm{~mm} \times 4 \mathrm{~mm}$. compressing rate was $2 \mathrm{~mm} / \mathrm{min}$, and the pre-compressing rate was $1 \mathrm{~mm} / \mathrm{min}$. After the test of all 10 groups, the maximum and minimum results should be ignored, then calculated the average of the rest of the results.

\subsubsection{The test of impact toughness}

We tested the impact toughness by the XJJ-5 impact testing machine. Before the test, the sample should be molded into an incomplete hexahedron structure with dimension of $10 \mathrm{~mm} \times 4 \mathrm{~mm} \times 4 \mathrm{~mm}$. The energy of impact is set as 4J. After the test of all 10 groups, the maximum and minimum result should be ignored, then calculated the average of the rest of the results.

\subsection{The friction-wear test}

We tested 9 groups of sample by friction-wear testing machine. The other component is stainless steel rim with the size that the outer diameter was $15 \mathrm{~mm}$ and the inner diameter was $10 \mathrm{~mm}$ and lubricated by 5201 silicone 
grease. The primitive revolving rate was set as $100 \mathrm{r} / \mathrm{min}$. The vertical stress is set as $100 \mathrm{~N}$. The rubbing length of each sample was $1 \mathrm{~km}$ in this trial then the group with the best performance was selected to have a test. In the later trial we set the stress as $100 \mathrm{~N}$ and revolving rate as 50r/min, 100 r/min, 150r/min and 200r/min orderly. Then we selected the group with the best performance to be tested. Controlling the revolving rate, the stress was set as $100 \mathrm{~N}, 200 \mathrm{~N}, 300 \mathrm{~N}$ and $400 \mathrm{~N}$ orderly and record each results which would be the standard for evaluating the affection on wear property from the vertical stress ${ }^{[3-6]}$.
We analyzed the micro-structure of the composite material $\mathrm{Go} / \mathrm{CF} / \mathrm{PTFE}$ crack and fracture area, and therefore we could analyze the the wear mechanism deeply.

\section{Results and discussion}

\subsection{Mechanical property}

The mechanical property test result of composite material $\mathrm{Go} / \mathrm{CF} / \mathrm{PTFE}$ is shown in Table 3.

\subsection{Micro- structure}

Table 3. Mechanical properties of composite material Go / CF / PTFE

\begin{tabular}{ccccccccccc}
\hline $\begin{array}{c}\text { Sample } \\
\text { number }\end{array}$ & $\mathbf{1}$ & $\mathbf{2}$ & $\mathbf{3}$ & $\mathbf{4}$ & $\mathbf{5}$ & $\mathbf{6}$ & $\mathbf{7}$ & $\mathbf{8}$ & $\mathbf{9}$ & $\mathbf{1 0}$ \\
\hline $\begin{array}{c}\text { Tensile } \\
\text { strength } \\
\text { /MPa } \\
\text { Bending }\end{array}$ & 15.96 & 19.39 & 15.97 & 9.22 & 19.86 & 13.15 & 9.61 & 17.72 & 9.58 & 7.45 \\
strength \\
$\quad$ MPa \\
$\begin{array}{c}\text { Compressive } \\
\text { strength } \\
\quad \text { MPa } \\
\begin{array}{c}\text { Impact } \\
\text { strength }\end{array}\end{array}$ & 20.67 & 21.54 & 18.20 & 16.07 & 21.47 & 18.01 & 14.52 & 20.11 & 17.32 & 10.70 \\
/MPa & 24.85 & 28.94 & 21.04 & 16.09 & 28.86 & 26.19 & 14.67 & 23.64 & 18.49 & 14.29
\end{tabular}

What is shown in Figure 3 is the strength value of composite Go/CF/PTFE when the mass fraction of Go was set as $1 \%$ and we could conclude that the addition of $\mathrm{CF}$ was able to improve the tensile strength, bending strength, compressive strength and impact strength. But if the CF content is too high, the strength will decrease. When the CF content was about $10 \%$, the tensile strength, bending strength, compressive strength and impact strength could be increased by $21.5 \%, 4.2 \%, 48 \%$ and $16.46 \%$, respectively. In the test of tensile property, the $\mathrm{CF}$ would work as skeleton to bear and deliver the load because of its high strength and elasticity modulus, and so when the CF content is about $10 \%$, the tensile strength will increase. As the CF content increased, the tensile strength would decrease considerably. The reasons are that the PTFE is a kind of organic material with stable property, and the interface issue between CF and PTFE is stubborn. Although CF have been disposed by KH-550 silane coupling agent, when the additional content is low the interface issue of CF won't be apparent, then the CF will perform as enhancement; when the CF content is more than $20 \%$, the interface issues will perform dominantly, so the tensile strength will decrease.

Figure 4 shows the strength value of composite material Go/CF/PTFE when the CF content is $10 \%$. The reasons are that the increasing of $\mathrm{CF}$ content will extrude the interface issue between CF and PTFE. It would lead to amounts of defect inside the sample, and therefore the strength would decrease slightly.

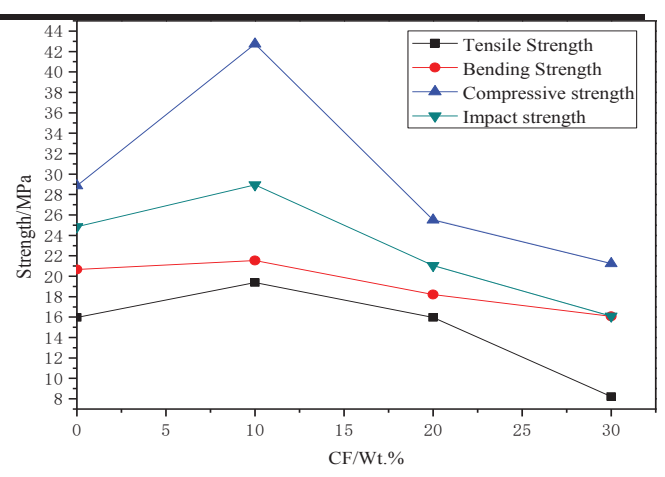

Figure 3.Dependence of mechanical properties on CF content of the Go/CF/PTFE composites with the graphene mass fraction of $1 \%$

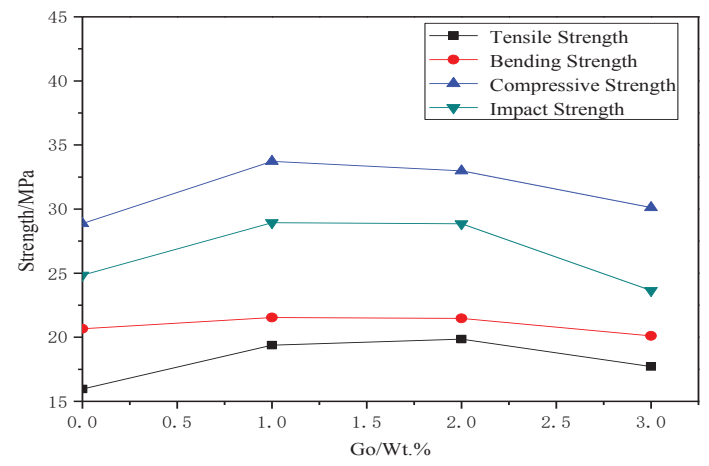

Figure 4. Dependence of strength on Go content of the $\mathrm{Go} / \mathrm{CF} / \mathrm{PTFE}$ composites with the carbon fiber mass fraction of $10 \%$ 


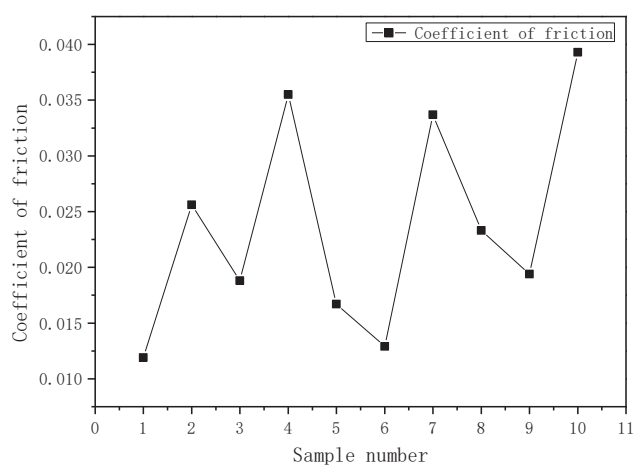

Figure 5. Friction coefficients of the Go/CF/PTFE composites of different samples tested at a pressure of $100 \mathrm{~N}$, with a rotation speed of $100 \mathrm{r} / \mathrm{min}$

Figure 5 has shown all stable friction coefficient value of each trial groups. It can be concluded that the addition of $\mathrm{CF}$ and Go could increase the value of stable friction coefficient. The tribological property of the composite material is affected by the original property of additional phase and the interface issue between additional phase and matrix. The high strength and hardness of CF would increase the hardness of composite material, and then increase the friction torque and friction coefficient. CF is a kind of new material with very low friction coefficient

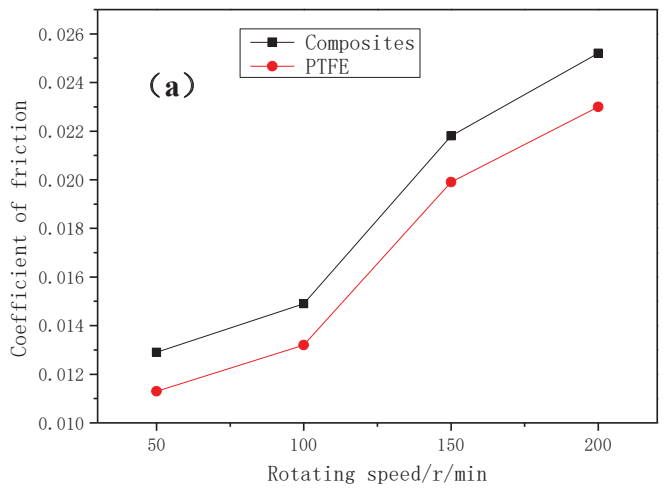

and the self-fabrication property will diminish the friction coefficient when $\mathrm{CF}$ is used as additional phase. When the content of $\mathrm{CF}$ and Go is low, the interface issue of the additional phase would not be obvious and the self-fabrication of CF will neutralize a part of the increase of friction coefficient which is attributed to $\mathrm{CF}$ content. So the increase of friction coefficient is not remarkable. But with increasing the additional phase content, the interface issue between additional phase and matrix will be more and more obvious. Meanwhile, the increase of friction coefficient will depend largely on the interface issue. When the Go content is not more than $1 \%$, the friction coefficient will be large when the CF content is $10 \%$ and $30 \%$, and when $\mathrm{CF}$ content is $20 \%$ the friction coefficient will decrease $26.6 \%$ and $50.1 \%$ compared with the friction coefficient when CF content is $10 \%$ and $30 \%$. The former trends are same when Go content is $2 \%$ and $3 \%$. If the CF content is not more than $20 \%$, you can find out the law that how Go affected the friction coefficient just like what CF content did. When the Go content is $2 \%$, the stable friction coefficient will decrease by $31.4 \%$ and $33.5 \%$ compared with stable friction coefficient when Go content is $1 \%$ and $3 \%$.

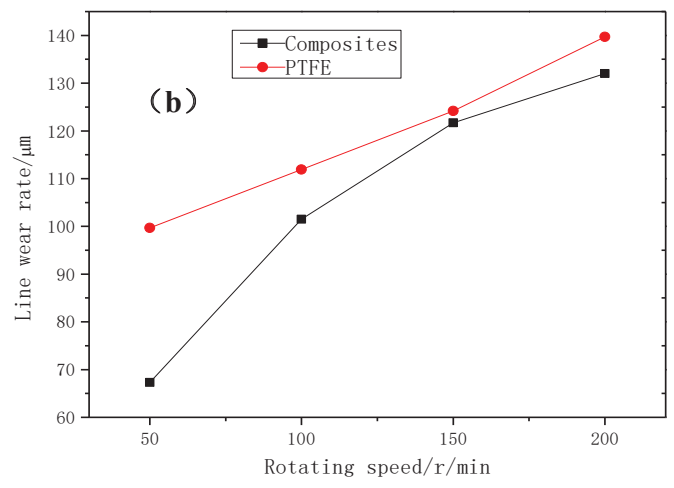

Figure 6. Coefficient of friction (a) and wear weight (b) for composite sample at pressure of $100 \mathrm{~N}$

Figure 6 shows the composite wear property (Figure 8(a)) in various revolving rate when the stress is $100 \mathrm{~N}$, and also shows that as revolving rate(Figure $8(\mathrm{~b})$ ) increases, the friction coefficient and Line wear rate will increase as well. The friction coefficient of composite material is larger than PTFE, but the line wear rate of composite material is lower. It proves that the friction coefficient of composite material is as low as the friction coefficient of PTFE. The additional phase improves the wear resistance property of PTFE, because the addition of CF can harden the surface of composite material, and the hard surface is able to prevent efficiently matrix from forming the completed wear film on the other rubbing component. Then the wearing capacity would decrease which is attributed to the stripping of wear film. Especially with the $50 \mathrm{r} / \mathrm{min}$ revolving rate, the line wear rate decreased by $50.8 \%$. The friction coefficient and line wear rate did not increase tremendously with the relatively low revolving rate. However, when the revolving rate was larger than $100 \mathrm{r} / \mathrm{min}$, the friction coefficient and line wear rate would increase considerably. That was because the increase of revolving rate led to the shear stress increase of $\mathrm{CF}$, and $\mathrm{CF}$ shed from the matrix will increase largely. Meanwhile, the increase of revolving rate would increase the wear surface chafe heat which could soften the matrix and then weaken the fixation between the matrix and CF. Under the conditions that the interface issue was not obvious, the chafe heat was generated by high revolving rate change the interface issue into an essential reason that affected the CF drop. The dropped CF acted as hard particle would intensify the wear phenomenon and increase the friction coefficient and line wear rate ${ }^{[7-9]}$.

Figure 7 shows the composite material tribological property according to different stress value with with the revolving rate of $50 \mathrm{r} / \mathrm{min}$, From Figure $7(\mathrm{a})$, it can be seen that the friction coefficient of composite material is higher than that of PTFE, and it would increase as the stress increases. From Figure 7(b), the line wear rate of composite material was lower than that of PTFE, and it would increase as the stress increases. It proves that the 
friction coefficient of composite material is as low as that of PTFE. Because of the addition of CF the surface got harder it prevented the wear film from forming. Therefore the high line wear rate was generated by dropped wear film would be diminished, and also the increased hardness would prevent abrasive wear happening. Consequently, the line wear rate of composite material was lower than that of PTFE.
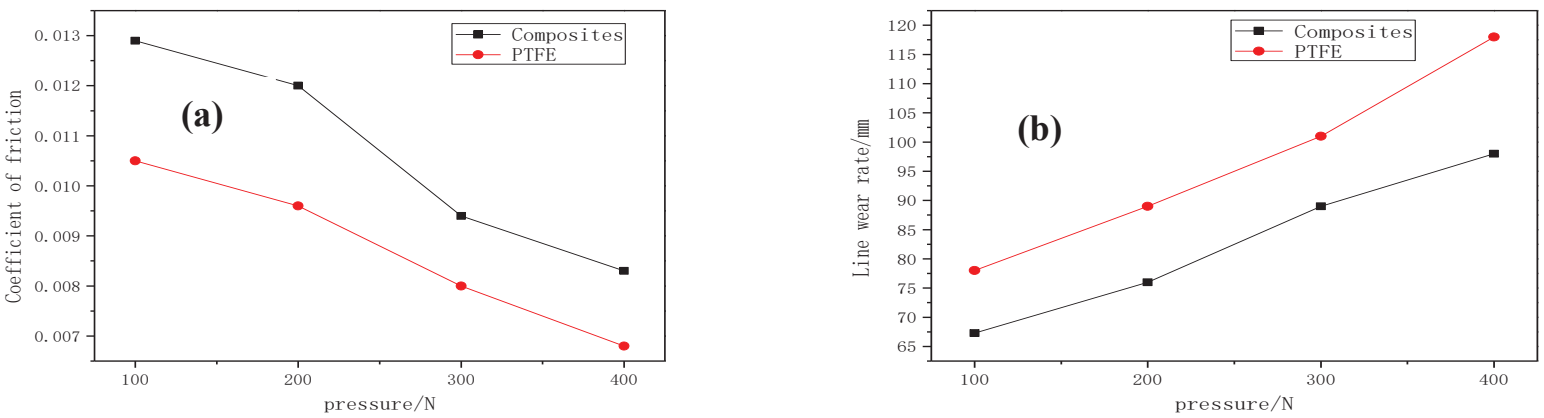

Figure 7. Coefficient of friction (a) and wear weight (b) for composite sample at 50r / min

\subsection{Micro- structure analysis}
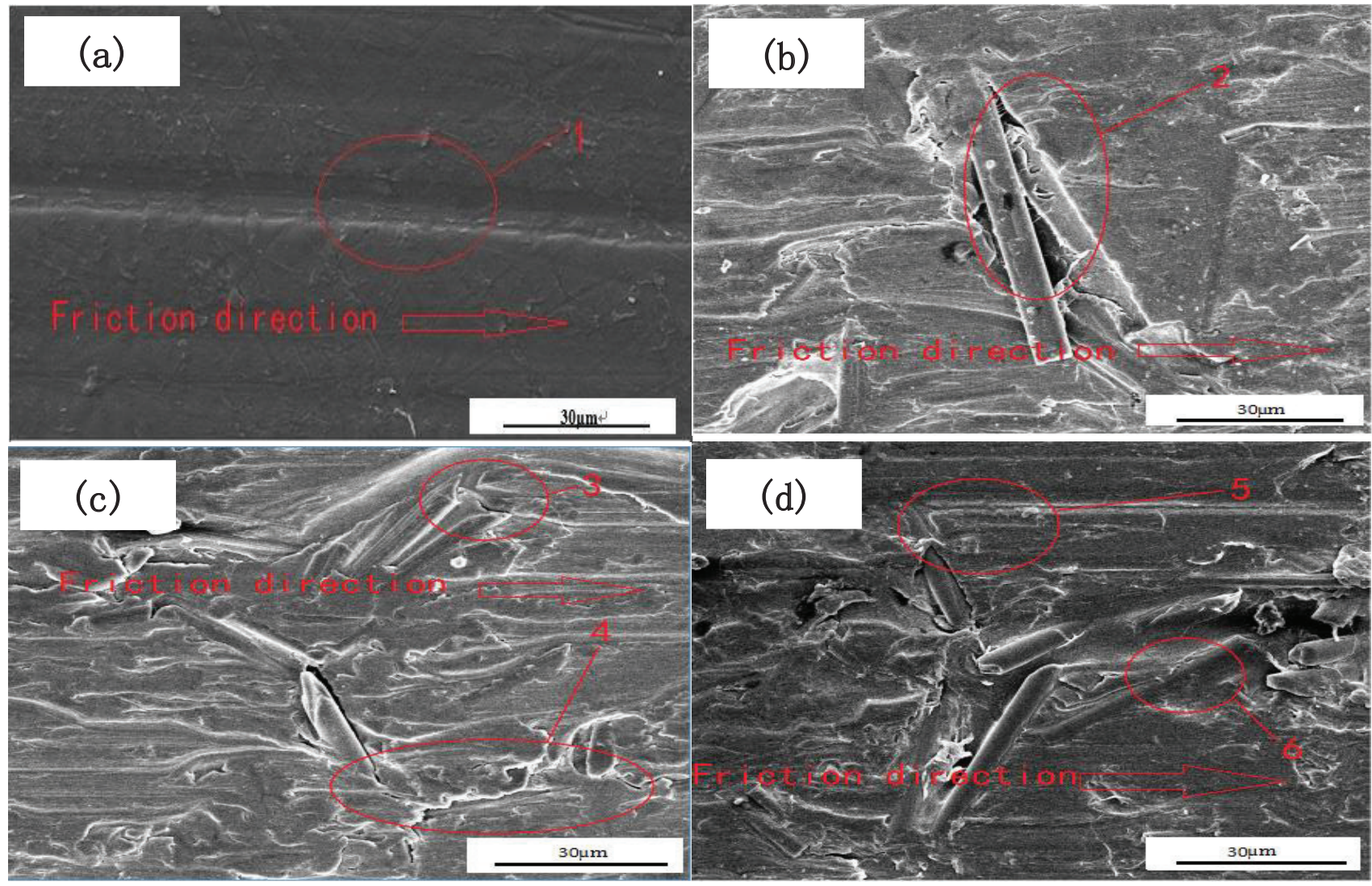

Figure 8. SEM wear morphology of PTFE and its composite material

(a)PTFE, 100r / min, 200N; (b)composite sample, 100r / min, 200N; (c) composite sample, 100r / min, 300N;(d) composite sample, $200 \mathrm{r} / \mathrm{min}, 200 \mathrm{~N}$

Figure 8 shows the microstructure of different composite material. The wear form was changedby the addition of CF and Go. Figure 8(a) demonstrated the wear surface of PTFE sample, and it can be found that the scratch on the area 1 was caused by the uneven wear facet of the stainless steel component in the micro level. The protruding part acted as the cutting edge scratched the surface, the procedure which is called plowing effect ${ }^{[10-12]}$.
After disposing by KH-550 silane coupling agent, the reinforcement $\mathrm{CF}$ prevented the matrix from wearing and the $\mathrm{CF}$ of the composite material sample(b) on area 2 would shed nearly. It have been supposed that it was caused by two reasons: firstly, after disposing by $\mathrm{KH}-550$ silane coupling agent, the interface issue between $\mathrm{CF}$ and matrix was not good and the CF could not inset the matrix tightly; secondly, the protruding part of the 
rubbing component kept cutting the rubbing surface during the trial, and then it brought a shear force to the rubbing surface. So the CF in the matrix would undertake the load and diminish the wear and the CF whose form was vertical to the rubbing orientation would suffer from the shear force. After being loaded for a long time, the crack would take place first on the loosest combination part between $\mathrm{CF}$ and matrix(shown in area 3 in Figure 10 (c)) and the crack would keep expanding during the rubbing procedure till the loosest part shed completely. The addition of $\mathrm{CF}$ would change the wear form and the plowing effect which took place on the material surface would turn into a kind of mixed wear effect that includes plowing effect and fatigue wear. Area 4 in Figure 10 (c) shown that the semi-enveloped crack had took place, because the wear surface was forced by the shear force for a long time and the crack source took place on the weak under area of $\mathrm{CF}$. The shear force would keep the crack source expanding and would cause the crater on the material surface. The CF which was non-paralleled to the rubbing orientation would prevent the crack happening because of the original high strength. Area 5 on Figure 8 (d) has shown the CF could prevent the matrix from plowing effect and then the wear resistance of composite material would be improved. Area 6 on Figure 8 (d) shows that $\mathrm{CF}$ was higher than the surrounding matrix, because the surrounding matrix would be wore firstly. The load-bearing function would be more dominant than wear resistance function. When the matrix of CF upper part was wore off, the CF was exposed on the rubbing surface. At the same time, $\mathrm{CF}$ and rubbing component contacted directly,so $\mathrm{CF}$ which has great wear resistance property kept matrix from wearing. When CF was wore off completely, the matrix and rubbing component would contact directly. The circulation of the former process would form the entire rubbing and wear process ${ }^{[13-16]}$.

Figure 9. Carbon fiber at high magnification

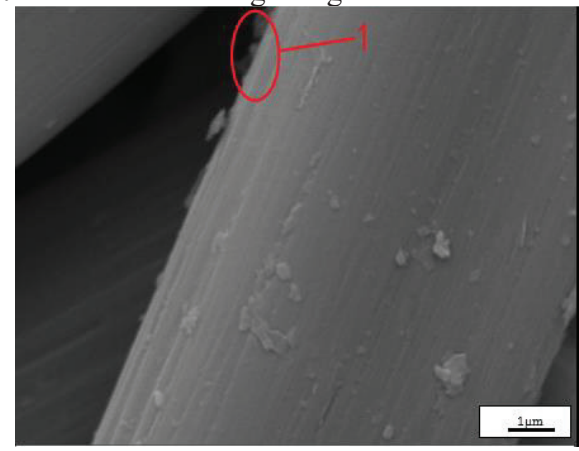

As a kind of self-fabricated material, $\mathrm{CF}$ would resist the wear when it was added into the composite material. The interface issue would be stubborn when inorganic Go was added into organic PTFE. This paper disposed the Go by silane coupling agent and improved the interface issue on the contact facet among Go, CF and PTFE. The combination between Go and $\mathrm{CF}$ has been shown in area 1 in Figure 9. It can be found that the $\mathrm{CF}$ which has plicated lamellar structure combined CF tightly. During the trial, the wear would be resisted by the excursion between layers, which is attributed to CF plicated lamellar structure.

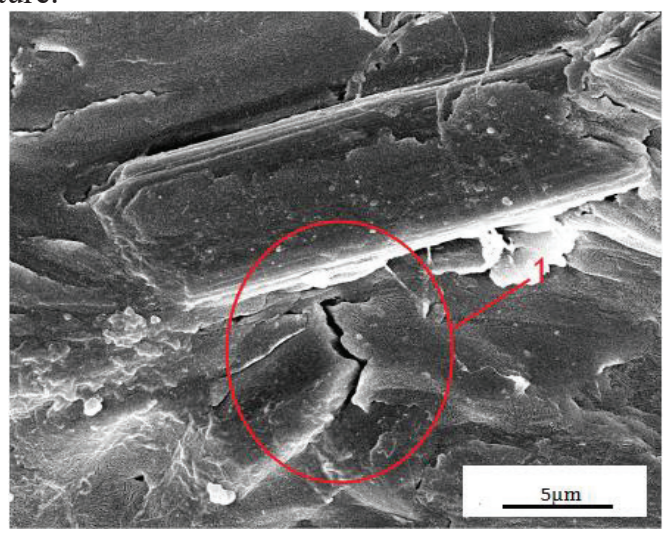

Figure 10. Pinning of carbon fibers

Figure 10 shows the affection form of $\mathrm{CF}$ among the matrix. Because the composite material sample was imposed by a shear force for a long time, the crack source would occur in the weak area of the material and then develop in a certain direction until it arrived at one side of $\mathrm{CF}$ which worked as pinning and prevented the material from shedding. When there were more than two cracks in different orientations expanding in one certain direction to one side of CF but did not intersect with each other, CF would worked as bridge to prevent the expansion efficiently as well as spinning. When force was accumulated to a certain extent, the cracks expanding path would be diverged from the original one by CF spinning and bridge affection. The new path would be parallel to the outer profile of CF. Finally, CF would shed completely, and therefore the wear would be more and more intensive. So the conclusion is that the interface issue between $\mathrm{CF}$ and PTFE would affect the tribological property of composite material considerably ${ }^{[17]}$.

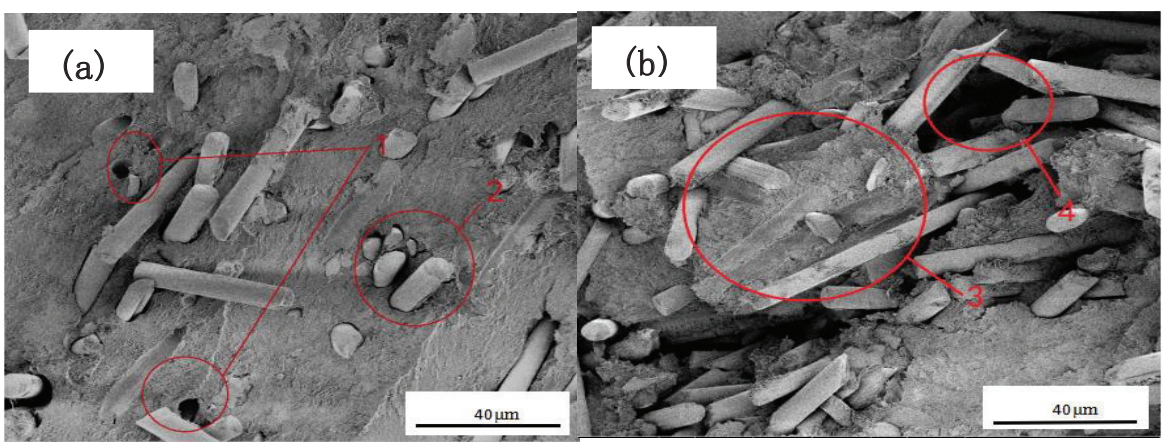

Figure 11.Composites Specimen Impact Section: (a) CF losening; (b) CF aggregate 
Figure 11 shows the impact section micro-structure of composite sample. We can conclude that the interface issue was not good from area 1 in Figure 11(a). CF was extracted out from the material when it was impacted. The combination between $\mathrm{CF}$ and matrix would turn to be loose. Maybe it was caused by the incomplete disposition by silane coupling agent, or the silane coupling agent disposition couldn't improve the interface issue between $\mathrm{CF}$ and PTFE. The tight combination between $\mathrm{CF}$ and matrix which is shown on area 3 in Figure 11 (b), which proved that the interface issue was solved seemingly. What is shown on area 2 in Figure 11 (a) is that the mid area of $\mathrm{CF}$ has been broken, which proved that $\mathrm{CF}$ could strengthen the matrix. Area 4 in Figure 11 (b) has shown the gaps in composite material sample. Maybe it was caused by the fast compressing rate of cold-press molding, or the liquid evaporation during sintering process which was attributed to the halfway drying of sample .

\section{Conclusion}

(1) The addition of CF and Go improved the strength property of composite material. When the content of $\mathrm{CF}$ and Go was $10 \%$ and $1 \%$, the strength of sample would be improved, but the excessive addition of CF and Go would cause the sudden decrease of strength.

(2) .The addition of CF and Go has changed the wear form of composite material, and it would turn into a kind of mixed wear effect that includes plowing effect and fatigue wear from the single plowing effect.

(3) Working as pinning and bridging, the Go which distributed uniformly in the matrix was able to improve the resistance and substantially resist the propagation of crack efficiently, and therefore to a certain degree the intensity of composite material was enhanced and its life span was prolonged.

\section{Acknowledgments}

This work was supported by the National Natural Science Foundation of P.R. China for the financial support (ID: 51372101, 51405195), Distinguished Middle-Aged and Young Scientist Encourage and Reward Foundation of Shandong Province (ID: ZR2016EMB01) and Taishan Scholar Engineering Special Funding (2016-2020).

\section{References}

1.Cai Xian-bin, Liu Xiu-bo.Study on Friction and Wear Properties of Polytetrafluoroethylene Composites [J]. Chemical Industry Management, 2015 (30): 15-15.

2.Wang Yong-hu, Wang Ling-juan, SONG Liming, et al.Studies and properties of graphene-polytetrafluoroethylene nanocomposites [J]. 3.Chemical Production and Technology, 2014, 21 (2): 12-14.

4.Zhu En-bo.Study on the preparation and properties of polytetrafluoroethylene composites modified by fiber and powder filling [J]. Jiangsu University, 2010.
5.Yan Ling, Wang Wen-dong.Application and Application of Carbon Fiber Filled Polytetrafluoroethylene [J]. Chinese Journal of Organic Chemistry, 2005 (3): 23-25.

6.Shi Guo-jun, LI Cui, Yuan Yue.Preparation and tribological properties of polytetrafluoroethylene composites co-filled with mullite and carbon fiber [J]. Journal of Materials Science, 2016, 33 (9): 1886-1898.

7.Jiang Bo,Zhou Qian-qian,Zhu Ai-ping, et al. The thermal expansion and mechanical properties of erilite-glass fiber / polytetrafluoroethylene composites under friction and wear $[\mathrm{J}]$. Chinese Journal of Composites, 2016, 33 (9): 1999-2005.

8.Shang Guan -qian .Study on tribological properties of rare earth modified carbon fiber reinforced polytetrafluoroethylene composites [D]. Shanghai Jiaotong University, 2007.

9.Wen Qin-shi, Huang Ping. Tribology [M]. Tsinghua University Press, 2012.

10.Gu Na. Study on Friction and Wear Properties of Polytetrafluoroethylene Composites [D]. Shandong University, 2009.

11.Chen Zhong-hua, Wang Jian-chuan, Yu Fei, et al.Preparation and thermal properties of graphene / melamine resin composites $[\mathrm{J}]$. Functional Materials, 2015, 46 (1): 1125-1128.

12.Yang Wen-bin, Zhang Li, Liu Jing-wei, et al. Progress in the preparation and application of graphene composites [J]. Materials Engineering, 2015, 43 (3): 91-97.

13.Kuzharov A S. Polytetrafluoroethylene fiber-based composite antifriction coatings[J]. Industrial \&

Engineering Chemistry Research, 1993, 32(5):1072-1078.

14.Conte M, Igartua A. Study of PTFE composites tribological behavior[J]. Wear, 2012, 296(s 1-2):568-574.

15.Zhao Zhu,Qun Ji Xue.Friction and wear properties of metal powder filled PTFE composites under oil lubricated conditions[J].wear, 1997,210:151 156.

16.Beckford S, Mathurin L, Chen J, et al. The effects of polydopamine coated $\mathrm{Cu}$ nanoparticles on the tribological properties of polydopamine/PTFE coatings[J]. Tribology International, 2016, 103:87-94.

17.Jotaki K, Miyatake M, Stolarski T, et al. Tribological performance of natural resin urushi containing PTFE[J]. Tribology International, 2016. 